\title{
A Remote Field Course Implementing High-Resolution Topography Acquisition and Applications Applied to Geomorphology
}

\author{
Sharon Bywater-Reyes ${ }^{1}$, Beth Pratt-Sitaula ${ }^{2}$ \\ ${ }^{1}$ Department of Earth and Atmospheric Sciences, University of Northern Colorado, Greeley, Colorado, 80639, United States \\ $5 \quad{ }^{2}$ Education and Community Engagement, UNAVCO, Boulder, Colorado, 80301, United States \\ Correspondence to: Sharon Bywater-Reyes (sharon.bywaterreyes@unco.edu)
}

\begin{abstract}
.
The course "Geoscience Field Issues Using High-Resolution Topography to Understand Earth Surface Processes" was originally intended to be conducted in-person with both field data collection and analysis to meet the "field" component of the

10 University of Northern Colorado's Earth Science degrees (Environmental and Geology). With the 2020 world pandemic and cancellation of most in-person activities for 2020, the course was adapted for $100 \%$ online implementation with an optional one-day field campaign. To prepare for the changed delivery model, UNAVCO and the University of Northern Colorado collected GNSS data, drone imagery for use in structure from motion, and terrestrial laser scanning from a site near Greeley, Colorado USA on the Cache la Poudre River. These data were used in mock field campaigns and real analyses implemented 15 by students virtually through Zoom and Canvas. The objective of the course is to train students in manual and remote sensing methods of topographic data collection, including 1) GPS/GNSS surveys, 2) structure from motion (SfM), and 3) groundbased (terrestrial laser scanning, TLS) and airborne LiDAR. Course content focused on earth-surface process applications, but could be adapted to other applications. This was taught workshop style with the bulk of the instruction and application occurring within a 2-week period during the summer. Students from throughout North America attended the course, most

20 meeting Field Camp requirements required for graduation. Despite the challenging conditions, students met the majority of the National Association of Geoscience Teachers' Field Capstone Learning Outcomes.
\end{abstract}

\section{Introduction}

The COVID-19 pandemic forced most higher education courses to remote options (Ali, 2020), which posed a challenge for all disciplines. This limitation was particularly challenging for geoscience programs because of their field tradition, with many 25 United States (US) undergraduate geoscience programs requiring field camp or a field course for degree completion (Wilson, 2016). The majority of these courses were planned for in-person implementation and were quickly redesigned for remote delivery (most US universities closed campuses March 2020 and courses occurred May through August 2020). This manuscript describes one such course, "Using High-Resolution Topography to Understand Earth Surface Processes," which originally planned to teach terrestrial laser scanning (TLS) and structure from motion (SfM) data collection and analysis applied to 
30 geomorphic issues in a mixed field/classroom setting. The course implementation and curriculum were adjusted so that TLS, GNSS, and drone imagery for SfM were collected prior to the field course. Informational videos about the field site and data collection were provided to the students in addition to the pre-collected data for use in the course curriculum. The needed data were collected by Bywater-Reyes from University of Northern Colorado, in collaboration with UNAVCO (unavco.org), near Greeley, Colorado on the Cache la Poudre River. Other geomorphic datasets were drawn from UNAVCO and 35 OpenTopography (https://opentopography.org/) archives.

This course, and the activities it included, were contributed to the National Association of Geoscience Teachers (NAGT; nagt.org) Designing Remote Field Experiences Collection. At the outset of the pandemic, NAGT and partners recognized the critical need for community collaboration on making the transition to remote field teaching and supported an initiative to crowd 40 source curriculum development. The resulting activities and courses, including the one descripted in this paper, were compiled on the NAGT website (https://nagt.org/nagt/teaching_resources/field/designing_remote_field_experie.html). The overall course is at https://serc.carleton.edu/NAGTWorkshops/online_field/courses/240348.html and the individual activities were linked within the course page as well as being contributed individually to the Online Field Teaching Activities collection (https://serc.carleton.edu/NAGTWorkshops/online_field/courses/240348.html).

45

The objective of the course was for students to learn manual and remote sensing methods of topographic data collection, including 1) GPS/GNSS, 2) structure from motion (SfM), and 3) ground-based (terrestrial laser scanning, TLS) surveying and airborne LiDAR use. Course content focused on earth-surface process applications, but could be adapted to other geoscience topics. The course was taught workshop style with the bulk of the instruction occurring within a 2-week period during the

50 summer. Synchronous lectures were conducted via Zoom and course content distributed via Canvas. Several students attended an optional in-person field collection campaign. The course culminated in a final project where students were able to explore the Poudre River data or another data set of their choosing.

UNAVCO runs the National Science Foundation (NSF) and National Aeronautics and Space Administration (NASA) geodetic 55 facility (GAGE: Geodetic Facility for the Advancement of Geoscience). As such, its primary mission is to support geodesy data collection and research, but it also provides educational support (including data acquisition, short courses, and curriculum) to the broader geodesy and geoscience communities. The teaching activities developed for this course were adapted from UNAVCO's GEodesy Tools for Societal Issues (GETSI; https://serc.carleton.edu/getsi/index.html) modules: Analyzing High Resolution Topography with TLS and SfM (https://serc.carleton.edu/getsi/teaching_materials/high-rez-topo/index.html) and

60 High Precision Positioning with Static and Kinematic GPS/GNSS (https://serc.carleton.edu/getsi/teaching_materials/highprecision/index.html) 
Fieldwork, while critical to building students' self-efficacy and problem-solving skills (Elkins and Elkins, 2007), can pose a barrier to diversifying the geosciences because of ableism (Carabajal et al., 2020), cost (Abeyta et al., 2020), cultural factors

65 (Hughes, 2015), racism (Abbott, 2006), and sexism (Fairchild et al., 2021) in the field. COVID-19 forced the geosciences to develop virtual field experiences, with a positive side effect of removing many of the aforementioned barriers to fieldwork completion. This course still allowed students to experience many of the positive affective factors incurred during field courses. This course was also the most diverse major's course the instructor, Bywater-Reyes, has ever taught with $24 \%$ (out of 25 students) under-represented minorities and $56 \%$ female students. Students also came from diverse geographic regions, with

70 students from six US states, one US territory, and one international student. At least $40 \%$ of students needed the course to meet degree requirements and most of the eight graduate students needed the expertise for their graduate research.

\subsection{Value of Course Topic}

High-resolution topographic datasets (structure from motion and ground-based and airborne lidar) are increasing useful for disciplines ranging from geomorphology, tectonics, to engineering and construction (Bemis et al., 2014; Passalacqua et al.,

75 2015; Robinson et al., 2017; Tarolli, 2014; Westoby et al., 2012). Use of high-resolution data in Earth Science education allows students to quantify landscapes and their change at submeter resolution (Pratt-Sitaula et al., 2017; Robinson et al., 2017). Understanding surface processes is listed as very important in the recent "Vision of Change in the Geosciences" with the objective "Students will be able to recognize key surface processes and their connection to geological features and possible natural and man-made hazards (Mosher et al., 2021)." Furthermore, use of multiple types of data allow students to practice

80 critical thinking skills such as which acquisition method is appropriate for difference scenarios and what errors are associated with different methods. Critical thinking, integrating diverse sources, and strong quantitative skills were all identified as very important skills for undergraduate geoscience students to master. Similarly, making inferences about the Earth system; making spatial and temporal interpretations; working with uncertainty; and developing field, GIS, computational, and data skills were all listed as very important geoscience skills for geoscience students to demonstrate (Mosher et al., 2021). Furthermore,

85 learning to collect, post-process, and analyse large datasets is a marketable transferable skill that prepares students for the job market, with cartography and photogrammetry job prospects being "excellent" according to the Bureau of Labor Statistics. For historically marginalized students, high-paying job prospects are particularly important (O’Connell and Holmes, 2011).

\subsection{Overview of Modules and Learning Objectives}

As part of the NAGT Teaching with Online Field Experiences collection, this curriculum attempts to meet as many of the

90 student learning outcomes, developed during the NAGT planning workshop (https://serc.carleton.edu/NAGTWorkshops/online_field/learning_outcomes.html), as possible. The outcomes met are italicized.

By the end of a capstone field experience, whether that experience is online or in-person, students should be able to:

- Design a field strategy to collect or select data in order to answer a geologic question. 
- Collect accurate and sufficient data on field relationships and record these using disciplinary conventions (field notes, map symbols, etc.).

- Synthesize geologic data and integrate with core concepts and skills into a cohesive spatial and temporal scientific interpretation.

- Interpret earth systems and past/current/future processes using multiple lines of spatially distributed evidence.

- Develop an argument that is consistent with available evidence and uncertainty.

- Communicate clearly using written, verbal, and/or visual media (e.g., maps, cross-sections, reports) with disciplinespecific terminology appropriate to your audience.

- Work effectively independently and collaboratively (e.g., commitment, reliability, leadership, open for advice, channels of communication, supportive, inclusive).

- Reflect on personal strengths and challenges (e.g. in study design, safety, time management, independent and collaborative work).

- Demonstrate behaviors expected of professional geoscientists (e.g., time management, work preparation, collegiality, health and safety, ethics).

The specific learning outcomes for the course were, after completion of the course, students should be able to:

- Make necessary calculations to determine the optimal survey parameters and survey design based on site and available time.

- Integrate GNSS targets with ground-based LiDAR and SfM workflows to conduct a geodetic survey.

- Process raw point cloud data and transform a point cloud into a digital elevation model (DEM).

- Conduct an appropriate geomorphic analysis, such as geomorphic change detection.

- Justify which survey tools and techniques are most appropriate for a scientific question.

The course was organized according to the following daily schedule and units:

\section{Unit 1: Structure from Motion (SfM) and GNSS}

- Day 1 - Getting started with Structure from Motion (SfM) photogrammetry (https://serc.carleton.edu/NAGTWorkshops/online_field/activities/238996.html)

- Day 2 - Introduction to GPS/GNSS

○ Unit 1: GPS/GNSS Fundamentals (https://serc.carleton.edu/getsi/teaching_materials/highprecision/unit1.html) - from the GETSI module High Precision Positioning with Static and Kinematic GPS/GNSS (https://serc.carleton.edu/getsi/teaching_materials/high-precision/index.html) 
- GPS/GNSS presentation

https://d32ogoqmya1dw8.cloudfront.net/files/NAGTWorkshops/online_field/activities/gnss_lectu re_presentation.pptx)

- GETSI's Accuracy \& Precision exercise (https://serc.carleton.edu/getsi/teaching_materials/highprecision/unit1.html\#prepared)

○ Post-processing GPS/GNSS Base Station Position

(https://serc.carleton.edu/NAGTWorkshops/online_field/activities/239147.html)

- $\quad$ Day 3 - SfM of Poudre River at Sheep Draw Reach

- Ground Control Points for Structure from Motion Activity

$$
\text { (https://serc.carleton.edu/NAGTWorkshops/online_field/activities/239349.html) }
$$

- Structure from Motion for Analysis of River Characteristics Activity (https://serc.carleton.edu/NAGTWorkshops/online_field/activities/239350.html)

- Day 4 - Working with Point Clouds in CloudCompare and Classifying with CANUPO (https://serc.carleton.edu/NAGTWorkshops/online_field/activities/240357.html)

- Day 5 - Report 1 - SfM Feasibility Report assignment (https://d32ogoqmya1dw8.cloudfront.net/files/NAGTWorkshops/online_field/courses/sfm_feasibility_report.v2.doc $\mathrm{x})$

- Day 6 - Optional Field Day (collected additional SfM dataset with local students who could participate) - no associated assignment

145

Unit 2: Lidar data (ground-based and airborne), point cloud versus raster forms, and difference detection

- $\quad$ Day 7 - Intro Terrestrial Laser Scanning (TLS; ground-based lidar) (https://serc.carleton.edu/NAGTWorkshops/online_field/activities/241028.html)

- $\quad$ Day 8 - Point Cloud/Raster Differencing and Change Detection

- Morning activity with course-collected SfM and TLS data - Point Cloud and Raster Change Detection (https://serc.carleton.edu/NAGTWorkshops/online_field/activities/241083.html )

- Afternoon activity with regional LiDAR from Colorado 2013 floods - DEM of Difference (https://serc.carleton.edu/NAGTWorkshops/online_field/activities/241138.html)

- Day 9 - Airborne LiDAR and additional data sources (https://serc.carleton.edu/NAGTWorkshops/online_field/activities/241410.html)

- Day 10 - Report 2 - Methods Comparison Report or report on their particular interest/research (https://d32ogoqmya1dw8.cloudfront.net/files/NAGTWorkshops/online_field/courses/methods_comparison_report. docx) 
- Day 11 - Presentations - students gave short presentations to the group based on their final report

\section{Unit 1: Structure from Motion (SfM) and GNSS}

On the first day of the course, students were introduced to Structure from Motion (SfM) as a means to create a high-resolution three-dimensional model. Students were also introduced to the concept of ground control for georeferencing the associated model. SfM is a photogrammetric technique that uses overlapping images to construct three-dimensional models with widespread research applications in geodesy, geomorphology, structural geology, and other sub-fields of geology (Passalacqua et al., 2015; Westoby et al., 2012). SfM can be collected from a handheld camera or an airborne platform such as an aircraft, tethered balloon, kite, or UAS (unmanned aerial system). SfM requires less expensive equipment and less field time, but more processing time, than Terrestrial Laser Scanning (TLS; ground-based lidar). Ground control points are key to both georeferenced the model and reduce distortions and errors (James et al., 2019). In low-vegetation field areas, it can yield a similarly valuable high-resolution topographic model applicable to a variety of geologic research questions. The resolution can be similar to TLS, with point densities usually hundreds of points per square meter (depending on camera-to-object distance; Westoby et al., 2012).

\subsection{Day 1: Getting started with Structure from Motion (SfM) photogrammetry}

On Day 1, students were introduced to SfM through an introductory presentation (Pratt-Sitaula, "Getting started with

Structure from Motion (SfM) photogrammetry";
https://serc.carleton.edu/NAGTWorkshops/online_field/activities/238996.html). Then, students used a camera such as on their smart phone and took overlapping photos of an object of interest. Using a compass bearing, inclination, and distance between ground control, students collected ground control coordinates (relative local coordinate system) to georeference their model. Students used Agisoft MetaShape software to post-process their photos and create the 3D point cloud. Students then evaluated the performance of their model by considering what went well and what might improve their product. Students also made recommendations for how SfM could be applied in the geosciences. An example student product (Figure 1) shows a successful model with annotations showing limitations and quality of the data. Teaching materials for this activity are published here: https://serc.carleton.edu/NAGTWorkshops/online_field/activities/238996.html. The assessment for this activity showed students' mastery in their modeling, with an average of $91 \%$.

\subsection{Day 3: Introduction to GPS/GNSS and the Cache la Poudre Site}

\subsubsection{Introduction to GPS/GNSS}

In the Day 1 activity, students used a relative local coordinate system to have a to-scale model. However, for real-world applications an absolute coordinate system is frequently preferable. As such, methods such as survey-grade Global Positioning 
190 Systems (GPS; US system) or more generally, Global Navigation Satellite System (GNSS), yield appropriate globally georeferenced ground control. As such, the GETSI module High Precision Positioning with Static and Kinematic GPS/GNSS was adapted by introducing students to appropriate methods in a lecture followed by a series of hands-on activities. In the morning of Day 2, students completed an activity comparing the accuracy and precision of various GNSS collection methods with using the module's Unit 1: GPS/GNSS Fundamentals Accuracy and Precision (Crosby and Lauer; https://serc.carleton.edu/getsi/teaching_materials/high-precision/unit1.html\#prepared). Assessment included a concept sketch of GNSS systems (Figure 2) and quantification and evaluation of accuracy and precision of different grades of GNSS and recommendations for appropriate applications of each. Students mastered these tasks, with course assessments of $88 \%$ and $85 \%$, respectively.

\subsubsection{Introduction to Cache la Poudre Field Site}

200 In the afternoon of Day 2, students were introduced to the field site and methods used for data collection at the Cache la Poudre field location. The UNAVCO-UNC team had visited the Cache la Poudre River at Sheep Draw Open Space (City of Greeley Natural Areas) in northern Colorado some weeks earlier in order to collect the data. According to the Coalition for the Poudre River Watershed, "The Cache la Poudre River Watershed drains approximately 1,056 square miles above the canyon mouth west of Fort Collins, Colorado. The watershed supports the Front Range cities of Fort Collins, Greeley, Timnath and Windsor. In an average year, the watershed produces approximately 274,000 acre feet of water. More than 80 percent of the production occurs during the peak snowmelt months of April through July" (https://www.poudrewatershed.org/cache-la-poudrewatershed).

In 2013, the Front Range and plains of Colorado experienced extensive flooding. The region received the average annual rainfall in one week (Gochis et al., 2015). There was extensive damage to infrastructure and in some cases the erosion

210 of 1000-years' worth of weathered material (Anderson et al., 2015). Near Greeley, significant portions of the Poudre trail were impacted as the river topped its floodplain and eroded its banks. The study site is adjacent to the Poudre Trail, with portions of the former trail eroded into the river and the current trail rerouted around the 2013-developed river course.

The UNAVCO-UNC team collected High Precision Positions with Static and Kinematic GPS/GNSS for use in ground control points for the associated SfM activity (Day 3). The UNAVCO-UNC team set up a base station receiver over an

215 unknown point (Figure 3). The associated assignment has students use GNSS high precision point postprocessing methods to establish a base station used to establish a control point for a kinematic survey (establishing ground control points used in SfM activity on Day 3).

Students watched a video (Video 1; https://youtu.be/EZ5I8Ge8YjI) introducing the field site and then a video introducing the GNSS methods (Video 2; https://youtu.be/Xpj1QJf8AkY). Then, using the pre-collected base-station data, students complete as assignment postprocessing for the static position, through the activity "Post-Processing GPS/GNSS Base Station Position" https://serc.carleton.edu/NAGTWorkshops/online_field/activities/239147.html. Students submit the base station file to the Online Positioning User Service (OPUS), the National Geodetic Survey (NGS)-operated system for baseline 
processing of standardized RINEX files into fixed (static) positions. Students interpret the output in a relevant coordinate system and state the errors associated with the position. On Day 3, students use kinematic positions for the SfM ground control network and in SfM post-processing.

\subsection{Day 3: Kinematic GNSS Survey Ground Control and SfM at Cache la Poudre Site}

\subsubsection{Kinematic GNSS Ground Control for SfM}

To substitute students having hands-on training setting up the GNSS base station kinematic rover and collecting ground control points in the field, data were pre-collected by setting up a Septentrio receiver over a known base station (established during

Post-processing GPS/GNSS Base Station Location exercise; $\quad$ Day https://serc.carleton.edu/NAGTWorkshops/online_field/activities/239147.html) and Real Time Kinematic positions collected over ground control targets. Since this exercise followed one that introduced SfM and GPS/GNSS methods and students were previously introduced to the site and methods with videos shot during data collection, students started with a group discussion on where ground control points at the site should be placed for their area of interest (Area 1 or Area 2; Figure 3). Students are

235 then given a text file of the $\mathrm{x}, \mathrm{y}, \mathrm{z}$ coordinates (UTM) collected by the UNAVCO-UNC team, and must import them into ArcGIS to create a ground control map. A follow-up discussion had students discuss the results of their map compared to the locations they discussed for placement in the discussion. They were asked to summarize the strengths and weaknesses of the implemented ground control plan at the site. This allowed them to meet the student learning outcome: "Develop an argument that is consistent with available evidence and uncertainty" as well as meeting those related to field and spatial relationships and communicate with written, verbal, and visual media.

\subsubsection{SfM of Cache la Poudre River at Sheep Draw Reach}

The authors had collected drone imagery of the Cache la Poudre site, for use in the Cache la Poudre SfM activity (https://serc.carleton.edu/NAGTWorkshops/online_field/activities/239350.html; https://doi.org/10.5069/G9416V78). Images were acquired using a DJI Mavic 2 Pro drone. Two flight paths were flown at altitudes of 40-m and 50-m and different grid orientations with $>70 \%$ overlap of adjacent photos with Pix4D capture. Before completing the SfM activity in MetaShape, students calculated the expected resolution of the point cloud resulting from the SfM workflow. Students were asked to assess what types of features or process on the Cache la Poudre study area they expect can be resolved with this resolution. They were asked what types of geomorphic questions they can answer with the dataset they will built.

Students picked either Area of Interest 1 or 2 for their SfM workflow (students with appropriate computing power can do the entire study area if they so choose). Students followed a MetaShape Guide to construct a georeferenced point cloud of their Area of Interest. Since students have already completed a MetaShape SfM model on Day 1, they were able to work through the procedure independently. Once their model was complete (example Figure 5), students were asked to answer a 

also asked to reflect once again on the ground control network used (2.3.1). Finally, students were asked to formulate a testable hypothesis related to processes on the Cache la Poudre River that they could answer with their dataset. For example, students investigated cutbank stable bank heights and angles. The activity described next allowed students to test their hypothesis and meet the first four NAGT capstone outcomes: 1) design and collect data to answer a geologic question; 2) collect data on field relationships and 3) synthesize spatially to 4) interpret a process using multiple lines of spatially distributed evidence.

\subsection{Day 4: Working with Point Clouds and Building Rasters}

\subsubsection{Using CloudCompare and Classifying with CANUPO}

On Day 4, students used the open-source software CloudCompare (http://www.danielgm.net/cc/) that allows for viewing and manipulation of point clouds. Students learned the basic operations and use in CloudCompare, and also use an open-source plugin called CANUPO (http://nicolas.brodu.net/en/recherche/canupo/) that allows for point cloud classification (Brodu and

265 Lague, 2012). Students learned to import point clouds into CloudCompare, classify the cloud, and took measurements on the cloud that allowed for hypothesis testing (formulated in 2.3). Students used the three-dimensional point cloud to take measurements to test their hypotheses. Finally, students classified their cloud into vegetation and ground. They compared this classification with the MetaShape classification. Students create a raster from ground points and export it for use in ESRI ArcGIS Map (2.4.2).

\section{$270 \quad$ 2.4.2 Introduction to Rasters in ArcGIS}

Students learned to import rasters in ESRI ArcGIS Map following the assignment "Working with Rasters in ArcGIS", within the Day 4 activity (https://serc.carleton.edu/NAGTWorkshops/online_field/activities/240357.html). After importing the raster, students familiarized themselves with viewing three-dimensional data in 2.5 dimensions. To aid in viewing, students created hillshade and slope maps. Students were asked to retest their hypothesis with tools available in ArcGIS and 2.5 dimensions

275 (e.g. measure tool, raster values). Students compared and contrasted applications with the three-dimensional point cloud versus 2.5-dimensional raster and summarized the appropriate uses and applications of each.

\subsection{Days 5 and 6}

On Day 5, students were given a work day to complete: "Unit 1: SfM Feasibility Report" (https://d32ogoqmya1dw8.cloudfront.net/files/NAGTWorkshops/online_field/courses/sfm_feasibility_report.v2.docx). Day 6 consisted of an optional field demo whereby students completed a GNSS ground control survey and Bywater-Reyes and colleagues collected drone images at the Poudre Learning Center (https://youtu.be/s5CGhk8GIOU; Bywater-Reyes, Sharon: Poudre Learning Center Project. https://doi.org/10.5446/54388). This provided an additional Cache la Poudre dataset students 

"Communicate clearly using written, verbal, and/or visual media (e.g., maps, cross-sections, reports) with discipline-specific terminology appropriate to your audience.” The evaluation focused on whether students followed scientific report formatting.

\subsection{Day 7: Introduction to Terrestrial Laser Scanning}

This exercise used pre-collected Terrestrial Laser Scanning (TLS; Bywater-Reyes, Poudre River at Sheep Draw (U-076); https://doi.org/10.7283/pstn-7r45) data whereby students were asked to compare and contrast this dataset with the previouslycreated SfM dataset, collected for the same geographic location (Cache la Poudre River) on the same day (Figure 7). Students were introduced to the TLS methodology through a video and lecture (https://serc.carleton.edu/NAGTWorkshops/online_field/activities/241028.html). Students visually inspected the datasets for similarities and differences. As with the SfM activity, students measured geomorphic features in the scene and compare their measurements for the two methods. Using skills gained in previous class activities, students classified the TLS cloud into vegetation and ground, exported the ground cloud as a text file, and create a raster that matched the specifications of the one made in the SfM activity (2.4.1). This allowed students to complete differencing in three-dimensions (cloud-to-cloud differencing) as well as raster differencing. Assessment was based on their completion of measurements and a discussion of methods comparison, including a group discussion.

\subsection{Day 8: Point Cloud/Raster Differencing and Change Detection}

\subsubsection{Point Cloud and Raster Change Detection}

300 On the morning of Day 8 students used the concepts of point cloud and raster differencing to compare their SfM and TLS results and interpret differences between the methods used for high-resolution topography collection (https://serc.carleton.edu/NAGTWorkshops/online_field/activities/241083.html). After being given a lecture "Point Cloud Differencing", students conducted a point cloud differencing of the SfM and TLS data for their area of interest on the Cache la Poudre River using CloudCompare (https://www.cloudcompare.org/doc/wiki/index.php?title=Distances_Computation)

305 using the M3C2 Plugin (Lague et al., 2012). Since these datasets were collected at the same place on the same day, differences between the datasets should be interpreted as error in one or both of the models. Students were asked to interpret the 3D differences between the datasets. The second lecture, "Raster Differencing" discusses best practices in preparing rasters for differencing. Students then used ArcGIS Raster Calculator tool to subtract one raster from the other (from same area of interest as the point cloud portion) making sure to use practices in raster creation and differencing (Wheaton et al., 2010). Students

310 interpreted the results and compared their differences conducted in 3D (point cloud differencing), and 2.5D (raster differencing). Students interpreted their results as an error analysis and discuss which dataset they think is more accurate (and why) and which method provided the most robust error analysis, practicing the associated NAGT capstone learning outcome 
(select data to answer a geologic question, collect accurate data, synthesize spatial and temporal data, develop argument consisten with evidence and uncertainty), with more rigor than in 2.4.2.

\section{2.7.2 Raster Geomorphic Change Detection}

Here, students used pre-existing LiDAR datasets to conduct a Digital Elevation Model (DEM) of Difference (DoD). It also served to introduce students to additional high-resolution topographic data (e.g., airborne lidar). In this assignment (https://serc.carleton.edu/NAGTWorkshops/online_field/activities/241138.html), the students used two lidar-derived raster datasets collected before and after the 2013 floods of the Colorado Front Range on a river (South St. Vrain Creek) that

320 experienced substantial geomorphic change. As such, students practiced their raster differencing skills in the context of geomorphic change detection (GCD) and also characterized their detection limit with a simple thresholding approach. This allowed students to focus on temporal spatial data - enhancing their skills related to NAGT's fourth learning outcomes.

\subsection{Day 9: Airborne LiDAR and additional data sources}

Following the in-depth exploration of two different high-resolution topographic methods (SfM and TLS) collected at the Cache

la Poudre River site, Day 9 (https://serc.carleton.edu/NAGTWorkshops/online_field/activities/241410.html) focused on airborne LiDAR and additional data sources (e.g., OpenTopography). After a lecture, students conducted an assignment using existing high-resolution datasets housed within OpenTopography (OT; https://opentopography.org/). First, student practiced downloading and viewing data from OT; second students conducted a topographic differencing exercise (Crosby et al., 2011), complementing the point cloud and raster differencing students conducted in Day 8 (section 2.6) of the course. On Day 10 of

330 the course, students finished their final report: "Unit 2: Using High-Resolution Topography to Address Societal Problems" and presented their final projects in Day 11. Students picked from a variety of options including improving methods from Unit 1 (SfM and TLS methods), adding new elements to Unit 1, choosing an additional exploration with the datasets collected on the optional field day, or using a different dataset such as airborne LiDAR. One student downloaded airborne LiDAR for the Cache la Poudre River and compared SfM, TLS, and airborne LiDAR for the same area! The final report allowed students to

335 learn from their previous report and Unit 1 performance and practice the NAGT outcome to "Communicate clearly using written, verbal, and/or visual media (e.g., maps, cross-sections, reports) with discipline-specific terminology appropriate to your audience" as well as "Work effectively independently and collaboratively (e.g., commitment, reliability, leadership, open for advice, channels of communication, supportive, inclusive)." Students were evaluated both on their execution of scientific report writing as well as the scientific method and hypothesis testing. 


\section{Lessons Learned and Implementation Recommendations}

This course was moved to virtual because of safety concerns surrounding COVID-19. However, the time commitment was kept the same as originally scheduled for in-person. As such, the course was about two weeks (for three credits) fulltime (all day plus homework), similar to what would be expected for a traditional in-person field-camp style course. This schedule proved exhausting with the online (Zoom lecture and office hours) commitments for the course (morning and afternoon)

345 combined with the computer-intensive nature of the assignments. In particular, challenges in this format included 1) computational access (e.g., a good enough computer) and 2) access to a time and space needed to complete the course. Several students dropped the course when they realized these constraints because of work and family obligations. We recommend, if the course is adapted in its entirety, to implement it as a longer interim session (minimum four weeks), quarter-, or semesterlong course. Additionally, having computers available in a lab or on loan with the appropriate computational and software needs would be helpful. If implemented as an intensive workshop, we recommend using at most four days' worth of material (as presented here). Any individual unit could be adapted as an assignment in an upper-division geomorphology or quantitative geoscience methods course. Despite the challenging schedule, the diverse set of students in the course were successful, with $48 \%$ of students receiving an $\mathrm{A}$ in the course, $17 \%$ a B, and $26 \%$ a C with the remaining $9 \%$ ( 2 students) receiving $\mathrm{D}$ or $\mathrm{F}$ grades.

This course operated under difficult conditions (e.g., global pandemic), but allowed students to meet degree requirements and accomplish most of the end-of-capstone field experience student learning outcomes outlined by NAGT.

Specifically, students practiced spatial and temporal data collection and interpretation, study design, hypothesis testing, error analysis, presenting information in appropriate written, verbal, and visual formats, and working collaboratively. The outcomes that received little attention were the last two: "Reflect on personal strengths and challenges (e.g. in study design, safety, time management, independent and collaborative work)" and "Demonstrate behaviors expected of professional geoscientists (e.g., time management, work preparation, collegiality, health and safety, ethics)." In the remote setting, it was difficult to replicate the as-needed problem solving and decision making that often arises in the field, and the reflection that follows. These would need to be emulated in a more explicit way than was accomplished here. Regarding the course-level student learning outcomes,

365 students certainly met them all. They are able to: 1) Make necessary calculations to determine the optimal survey parameters and survey design based on site and available time, 2) Integrate GNSS targets with ground-based LiDAR and SfM workflows to conduct a geodetic survey, 3) Process raw point cloud data and transform a point cloud into a digital elevation model (DEM), 4) Conduct an appropriate geomorphic analysis, such as geomorphic change detection, 5) Justify which survey tools and techniques are most appropriate for a scientific question. These skills are marketable in both research and the commercial workforce. 
Lastly, student feedback and requests for additional offerings of the course indicate student appreciation of the course. One student wrote the instructor, "I just wanted to thank you for the class. I have had an incredible journey during my university experience. Without this class being offered I truly do not know what I would have done. This has been a very trying time in my life and completing this course was the push I needed to continue through. I can't thank you enough for doing this. Not only offering the class but how flexible you were and understanding. Hands down one of the best professors I have had to date. You are an incredible teacher and I am very grateful that I took this class with you. Once again, from the bottom of my heart, thank you!"

\section{Acknowledgments}

380 We thank Keith Williams and Erika Schreiber (UNAVCO), Ara Metz, Chelsie Romulo, and James Doerner for field data collection support and City of Greeley and the Poudre Learning Center for field site access.

\section{References}

Abbott, D.: Disrupting the "whiteness" of fieldwork in geography, Singap. J. Trop. Geogr., 27(3), 326-341, doi:10.1111/j.1467-9493.2006.00265.x, 2006.

385 Abeyta, A., Fernandes, A. M., Mahon, R. C. and Swanson, T.: The true cost of field education is a barrier to diversifying geosciences, Earth ArXiv, 12 [online] Available from: https://eartharxiv.org/repository/view/2091/ (Accessed 13 August 2021), 2020.

Ali, W.: Online and Remote Learning in Higher Education Institutes: A Necessity in light of COVID-19 Pandemic, High. Educ. Stud., 10(3), 16, doi:10.5539/hes.v10n3p16, 2020.

390 Anderson, S. W., Anderson, S. P. and Anderson, R. S.: Exhumation by debris flows in the 2013 Colorado Front Range storm, Geology, 43(5), 391-394, doi:10.1130/G36507.1, 2015.

Bemis, S. P., Micklethwaite, S., Turner, D., James, M. R., Akciz, S., Thiele, S. T. and Bangash, H. A.: Ground-based and UAV-Based photogrammetry: A multi-scale, high-resolution mapping tool for structural geology and paleoseismology, J. Struct. Geol., 69(PA), 163-178, doi:10.1016/j.jsg.2014.10.007, 2014.

395 Brodu, N. and Lague, D.: 3D terrestrial lidar data classification of complex natural scenes using a multi-scale dimensionality criterion: Applications in geomorphology, ISPRS J. Photogramm. Remote Sens., 68, 121-134, doi:10.1016/j.isprsjprs.2012.01.006, 2012.

Carabajal, I. G., Atchison, C. L. and Atchison, C. L.: An investigation of accessible and inclusive instructional field practices in US geoscience departments, Adv. Geosci., 53, 53-63, doi:10.5194/adgeo-53-53-2020, 2020.

400 Crosby, C. J., Arrowsmith, J. R., Nandigam, V. and Baru, C.: Online access and processing of LiDAR topography data, in Geoinformatics, vol. 9780521897150, edited by G. R. Keller and C. Baru, pp. 251-265, Cambridge University Press, 
Cambridge., 2011.

Elkins, J. T. and Elkins, N. M. L.: Teaching geology in the field: Significant geoscience concept gains in entirely field-based introductory geology courses, J. Geosci. Educ., 55(2), 126-132, doi:10.5408/1089-9995-55.2.126, 2007.

405 Fairchild, E., Newman, H., Sexton, J., Pugh, K. and Riggs, E.: 'Not to be stereotypical, but .'. Exclusive and inclusive gendered discourses about geology field experiences, J. Gend. Stud., 1-13, doi:10.1080/09589236.2021.1924644, 2021.

Gochis, D., Schumacher, R., Friedrich, K., Doesken, N., Kelsch, M., Sun, J., Ikeda, K., Lindsey, D., Wood, A., Dolan, B., Matrosov, S., Newman, A., Mahoney, K., Rutledge, S., Johnson, R., Kucera, P., Kennedy, P., Sempere-Torres, D., Steiner, M., Roberts, R., Wilson, J., Yu, W., Chandrasekar, V., Rasmussen, R., Anderson, A. and Brown, B.: The great Colorado flood

410 of September 2013, Bull. Am. Meteorol. Soc., 96(9), 1461-1487, doi:10.1175/BAMS-D-13-00241.1, 2015.

Hughes, R.: An investigation into the longitudinal identity trajectories of women in science, technology, engineering, and mathematics, J. Women Minor. Sci. Eng., 21(3), 181-213, doi:10.1615/JWomenMinorScienEng.2015013035, 2015.

James, M. R., Chandler, J. H., Eltner, A., Fraser, C., Miller, P. E., Mills, J. P., Noble, T., Robson, S. and Lane, S. N.: Guidelines on the use of structure-from-motion photogrammetry in geomorphic research, Earth Surf. Process. Landforms, 44(10), 2081-

415 2084, doi:10.1002/esp.4637, 2019.

Lague, D., Brodu, N., Leroux, J., Rennes, G., Rennes, U. and Beaulieu, C. De: A new method for high precision 3D deformation measurement of complex topography with terrestrial laser scanner : application to the Rangitikei canyon ( $\mathrm{N}-\mathrm{Z}$ ), , 1-30, 2012.

Mosher, S., Harrison, W., Huntoon, J., Keane, C., McConnell, D., Miller, K., Ryan, J., Summa, L., Villalobos, J. and White,

420 L.: Vision and Change in the Geosciences: The Future of Undergraduate Geoscience Education, edited by S. Mosher and C. Keane, American Geosciences Institute. [online] Available from: https://www.americangeosciences.org/change/, 2021.

O'Connell, S. and Holmes, M. A.: Obstacles to the recruitment of minorities into the geosciences: A call to action, GSA Today, 21(6), 52-54, doi:10.1130/G105GW.1, 2011.

Passalacqua, P., Belmont, P., Staley, D. M., Simley, J. D., Arrowsmith, J. R., Bode, C. A., Crosby, C., DeLong, S. B., Glenn,

425 N. F., Kelly, S. A., Lague, D., Sangireddy, H., Schaffrath, K., Tarboton, D. G., Wasklewicz, T. and Wheaton, J. M.: Analyzing high resolution topography for advancing the understanding of mass and energy transfer through landscapes: A review, EarthScience Rev., 148, 174-193, doi:10.1016/j.earscirev.2015.05.012, 2015.

Pratt-Sitaula, B., Crosby, B. and Crosby, C.: Integrating topographic imaging into geoscience field courses, in Eos (United States), vol. 98, p. 14, American Geophysical Union., 2017.

430 Robinson, S. E., Bohon, W., Kleber, E. J., Arrowsmith, J. R. and Crosby, C. J.: Applications of high-resolution topography in Earth science education, Geosphere, 13(6), 1887-1900, doi:10.1130/GES01236.1, 2017.

Tarolli, P.: High-resolution topography for understanding Earth surface processes: Opportunities and challenges, Geomorphology, 216, 295-312, doi:10.1016/j.geomorph.2014.03.008, 2014.

Westoby, M. J., Brasington, J., Glasser, N. F., Hambrey, M. J. and Reynolds, J. M.: ‘Structure-from-Motion' photogrammetry: 
https://doi.org/10.5194/gc-2021-26

Preprint. Discussion started: 9 September 2021

(C) Author(s) 2021. CC BY 4.0 License.

(c) (1)

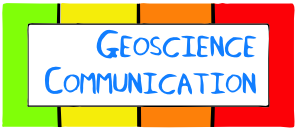

2012.

Wheaton, J. M., Brasington, J., Darby, S. E. and Sear, D. a.: Accounting for uncertainty in DEMs from repeat topographic surveys: improved sediment budgets, Earth Surf. Process. Landforms, 156(December 2009), n/a-n/a, doi:10.1002/esp.1886, 2010.

440 Wilson, C.: Status of the Geoscience Workforce 2016, American Geosciences Institute, Alexandria, Virginia. [online] Available from: https://store.americangeosciences.org/status-of-the-geoscience-workforce-2016.html, 2016. 
https://doi.org/10.5194/gc-2021-26

Preprint. Discussion started: 9 September 2021

(c) Author(s) 2021. CC BY 4.0 License.

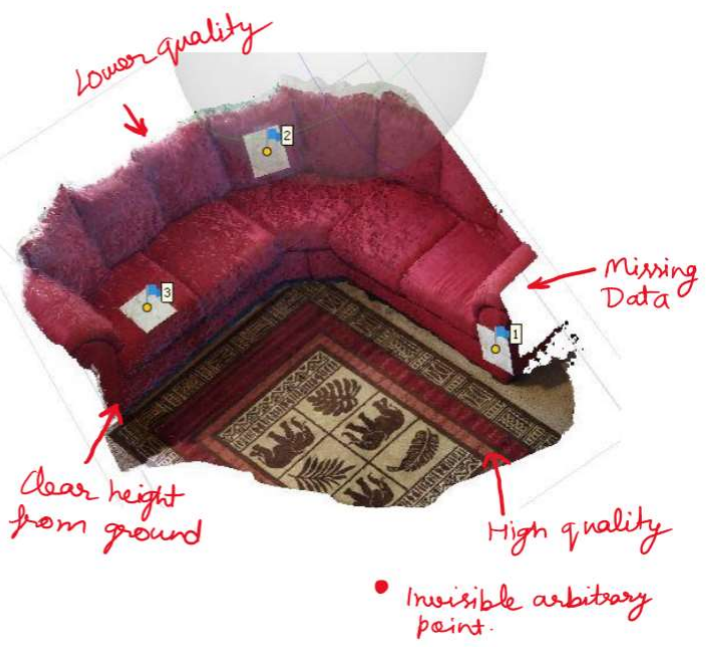

Figure 1: Student SfM product from Day 1 exercise where assessment (created by student in course; student not disclosed to comply with Institutional Review Board).

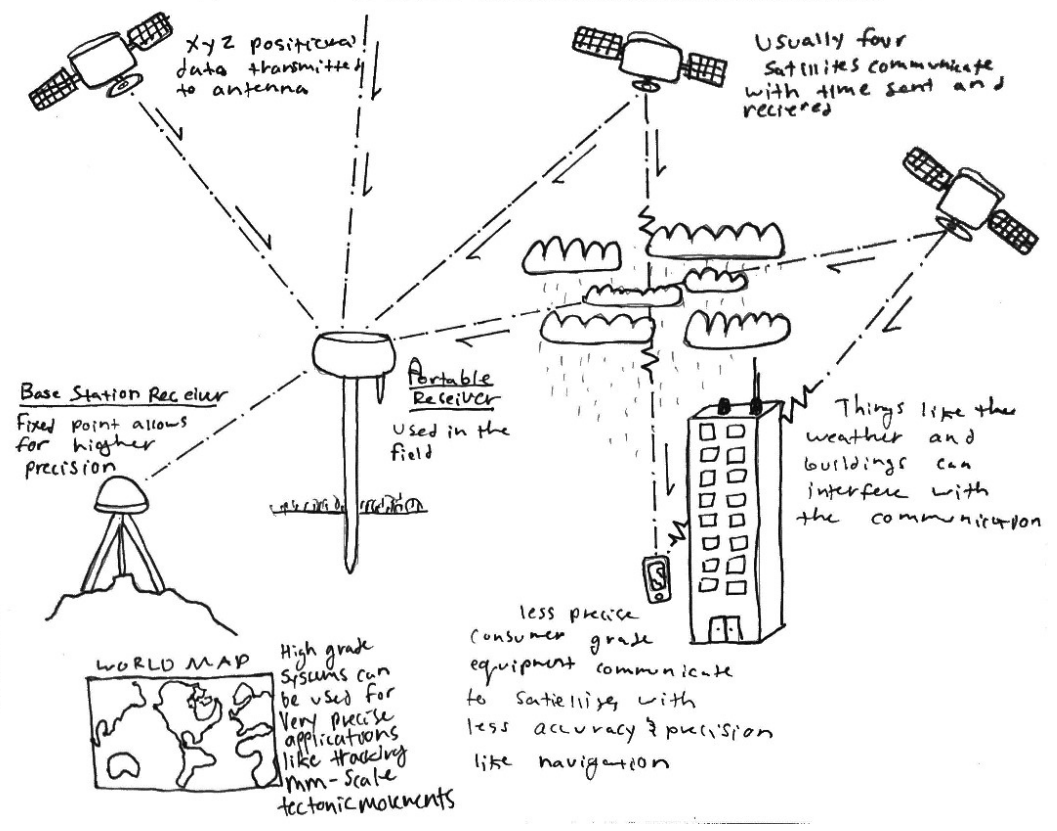


https://doi.org/10.5194/gc-2021-26

Preprint. Discussion started: 9 September 2021

(c) Author(s) 2021. CC BY 4.0 License.

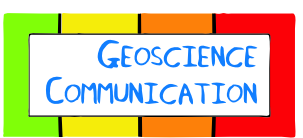

(c) (i)

Discussions

450

Figure 2: Student sketch of how GNSS works, including disruptions and applications thereof (created by student in course; student not disclosed to comply with Institutional Review Board).

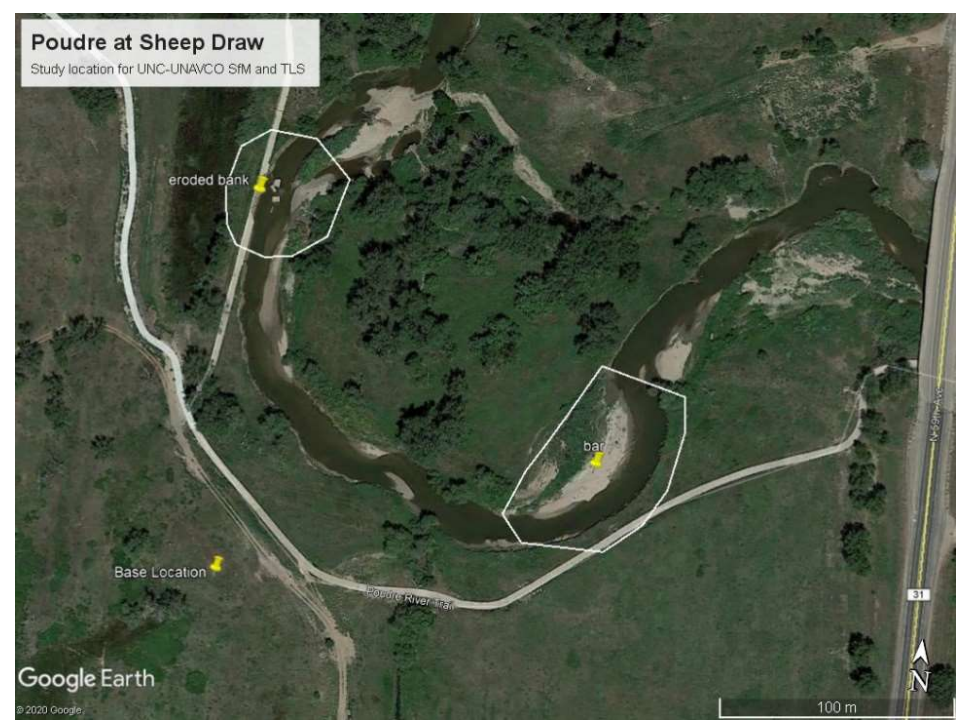

455 Figure 3. Inset: Map ( Google Earth) of the Cache la Poudre River Watershed, located in northern Colorado, US. The study site at Sheep Draw has two areas of interest, Area of Interest 1 on an eroded bank and Area of Interest 2, a cutbank and point bar.

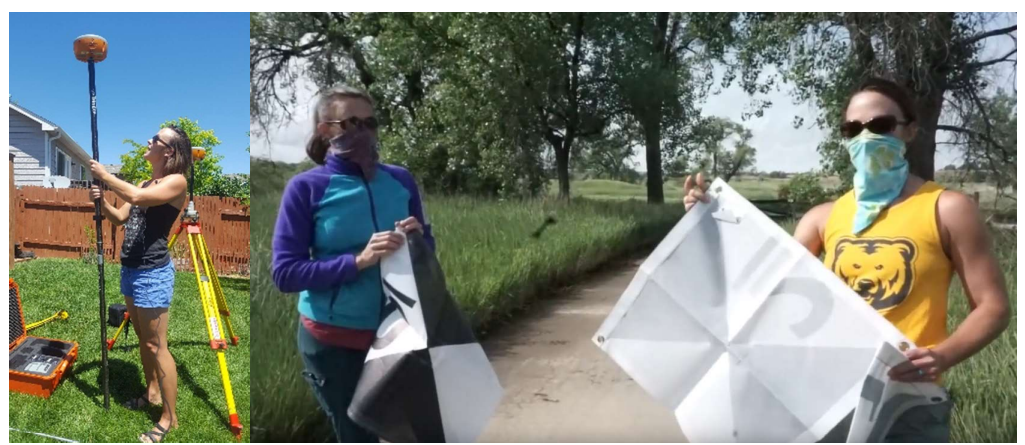

Figure 4. Base and Kinematic GNSS methods (left) and example of ground control (right) surveyed for use in GNSS and SfM activities. 
https://doi.org/10.5194/gc-2021-26

Preprint. Discussion started: 9 September 2021

(c) Author(s) 2021. CC BY 4.0 License.
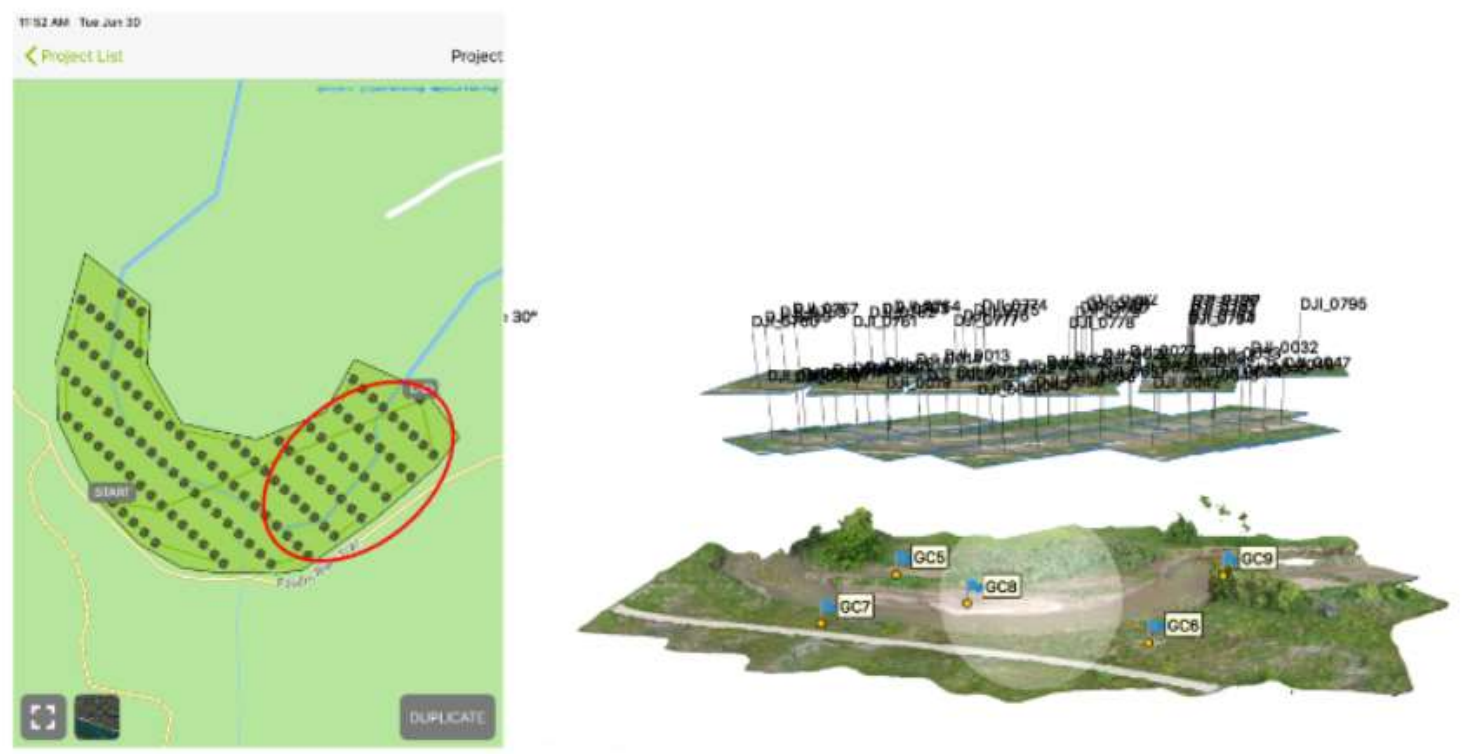

Figure 5. Example of a student's area of interest (left) picked and associated MetaShape georeferenced point cloud (right) of their area of interest (created by student in course; student not disclosed to comply with Institutional Review Board).

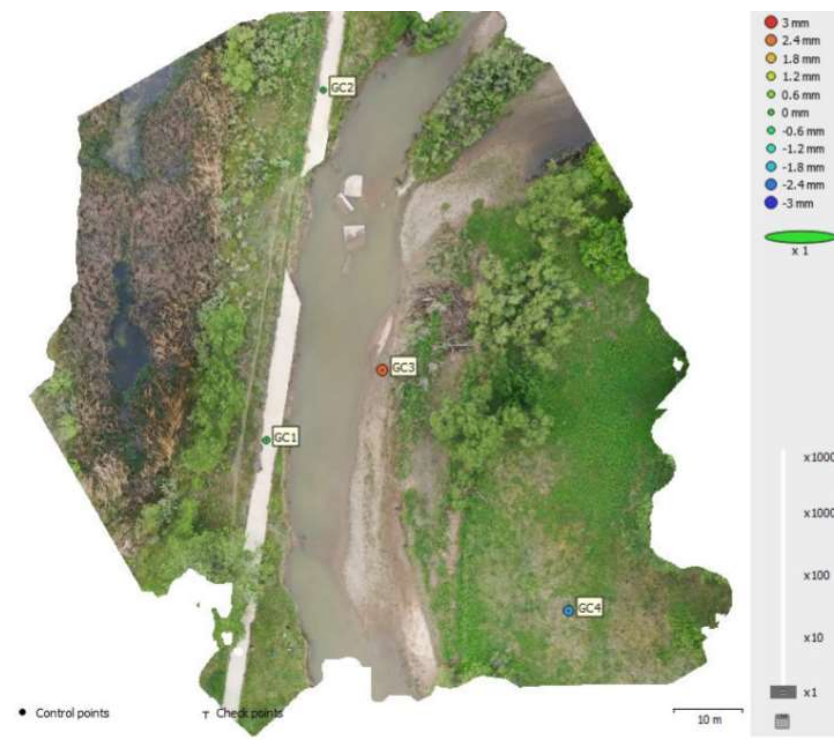

465 Figure 6. Example area of interest showing error analysis (created by student in course; student not disclosed to comply with Institutional Review Board). 
https://doi.org/10.5194/gc-2021-26

Preprint. Discussion started: 9 September 2021

(c) Author(s) 2021. CC BY 4.0 License.

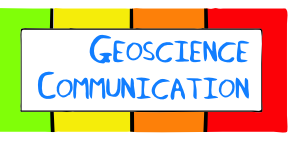

Discussions

(c) (i)

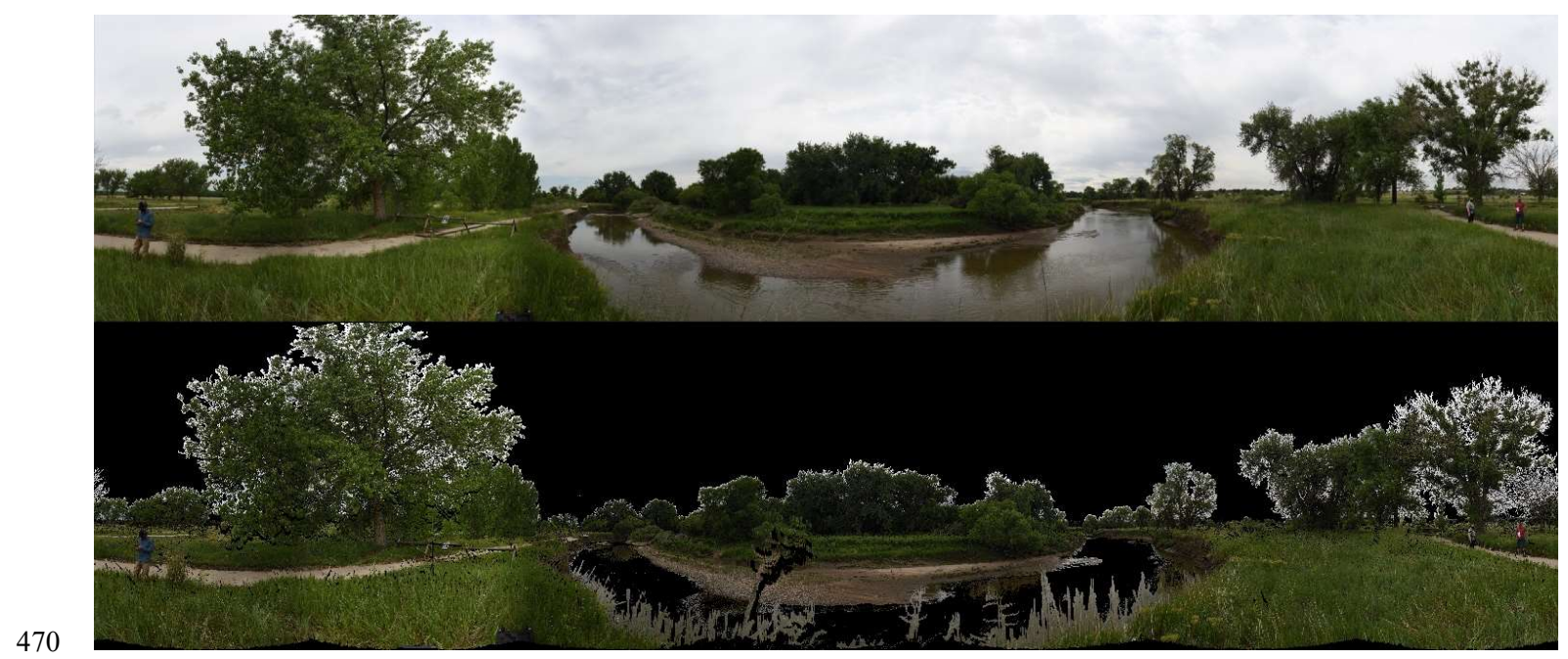

Figure 7. The top shows the Terrestrial Laser Scanner (TLS) photograph from a scan location whereas the bottom shows the associated point cloud at the Cache la Poudre River site. Courtesy UNAVCO. 